\title{
Quality protein maize (QPM) for school feeding in Ethiopia: stakeholders consultation, sensory evaluation and potential impact
}

\begin{abstract}
Recently there is an increased attention among policy and research practitioners on the link between school feeding programs (SFP) and agricultural development. Through purchases and procurement of locally produced foods, SFP are thought to enhance the domestic production and demand for food and stimulate local agricultural economy. Quality protein maize (QPM) varieties, which are being disseminated in Ethiopia by CIMMYT, are superior to conventional maize $(\mathrm{CM})$ varieties in their protein quality. However, for QPM to be adopted in SFP, sensory acceptance by the end-users should be assessed, specifically when the targets beneficiaries are young children. Furthermore, the potential challenges and opportunities for its supply to SFPs should be analysed by involving pertinent stakeholders involved in maize value chain. Thus, the objective of this study is to assess sensory evaluation of QPM among 95 adolescent girls in two primary schools in Ethiopia on a popular local porridge-like product Kinchie through central location testing, and also assess potential challenges and opportunities in QPM production and distribution through stakeholders' consultation. Results of sensory evaluation showed that Kinchie made from QPM varieties, both yellow QPM (BHPQY 545) and white QPM (AMHP 760Q), were much appreciated for aroma, taste and overall appreciations. Nevertheless, among QPM varieties, the students liked the Kinchie made from yellow QPM (BHQPY 545) more than Kinchie made from a white colored QPM (AMH 760Q) in all sensory attributes except appearance. The result also showed that the effect of order of food presentation had a significant and positive effect only for aroma $(\mathrm{P}<.05)$. Stockholder consultation result also showed that local maize grain producers and traders and other institutions involved in maize value chain were enthusiastic to engage in QPM production and supply through contract farming. In conclusion, consumer acceptance is unlikely to impede uptake and impact of QPM use in the place of CM varieties in SFPs.
\end{abstract}

Keywords: school feeding programs, quality protein maize, consumer acceptability, sensory evaluation, ethiopia
Volume 8 Issue 6 - 2018

\author{
Demissie Belayneh,' Senait Yetneberk, ${ }^{2}$ \\ Adefris Teklewold,' Hugo De Groote ${ }^{3}$ \\ IInternational Maize \& Wheat Improvement Center (CIMMYT), \\ Ethiopia \\ ${ }^{2}$ Sasakawa Global 2000, Ethiopia \\ ${ }^{3}$ International Maize \& Wheat Improvement Center (CIMMYT), \\ Kenya
}

Correspondence: Demissie Belayneh, International Maize \& Wheat Improvement Center (CIMMYT), P.O. Box 5689, Addis Ababa, Ethiopia, Tel +251929233547, Email d.belaynah@cgiar.org

Received: November 03, 2018 | Published: November 13,

2018

\section{Introduction}

Ethiopia is one of the most food insecurity countries in Africa where about 7 million school age children are living in food insecure parts of the country. ${ }^{1}$ Malnutrition is a serious public health concern for the country with about 44 percent of the children under five stunted. ${ }^{2}$ Recently the idea of using school feeding programs as a vehicle for agricultural development has gained momentum. ${ }^{3}$ The rationale behind school feeding programs based on the use of locallyproduced food is that they can provide a regular market opportunity and a reliable source of income for smallholder farmers. ${ }^{3-6}$ In Ethiopia, maize constitutes one of the major staple foods for the population, ranking first in total production and second in area planted. ${ }^{7}$ Nevertheless, conventional maize is deficient in tryptophan and lysine, which are essential amino acids for humans. ${ }^{8}$ Quality Protein Maize (QPM) are biofortified varieties that have improved protein quality- higher tryptophan and lysine levels. ${ }^{9-11}$ Meta-analysis of studies in various countries show that consumption of QPM as compared to conventional maize gave $8 \%$ increase in rate of growth in height and $9 \%$ increase in rate of growth in weight in infants \& toddlers with mild to moderate under-nutrition where maize was a significant part of the diet. ${ }^{12}$ Thus, promoting the use of QPM as a substitute for conventional maize in school feeding programs would not only address the prevailing amino acid deficiency in conventional maize but also serve as a cost-effective way to provide a dependable source of protein for school children.
Biofortification is a promising strategy to address the underlying cause of under nutrition, households' poor access to nutritious food. ${ }^{13}$ Furthermore, recent studies conducted with human subjects under controlled setting show that biofortification can have an impact on public health. For instance, a school child feeding trial in South Africa showed that consumption of orange-fleshed sweet potato, high in betacarotene, led to improvements in their vitamin A status. ${ }^{14}$ Likewise, a 9-month feeding experiment in the Philippines showed that frequent consumption of rice containing an extra 2.6 parts per million (ppm) of iron was efficient in improving body iron stores among iron-deficient women..$^{15}$ The impact of multiple micronutrient fortification, including iron, iodine, and beta-carotene (a precursor of vitamin A), was studied in KwaZulu-Natal, South Africa. Children receiving fortified biscuits for 43 weeks demonstrated improved short-term memory compared with children in the control group. ${ }^{16}$

Forbiofortified crops such as QPM to be used in SFPs as substitute for CM in Ethiopia, two issues must be addressed. First, does QPM fit into existing school feeding program or can they be adapted to fit in situations where conventional maize is used in school feeding programs as substitute? Secondly, as QPM can have different sensory characteristics, and some QPM varieties are yellow, are these attributes acceptable to school children? Furthermore, anecdotal evidence suggests that the opaque 2 gene has an effect on organoleptic characteristics especially making the dough more sticky. ${ }^{17}$ Understanding these issues and the relevance of QPM to the 
specific SFP program's effectiveness and sustainability are important pieces of information to derive policy and programmatic implications.

The objectives of this study were therefore:

a. To assess the potential of QPM in school feeding programs

b. To evaluate sensory appreciation of local food stuff made from QPM \& conventional maize varieties by school children and

c. To assess awareness among adolescent school girls about sources of major nutrition and QPM. In the following sections, the paper first reviews school feeding programs and its links to agricultural development.

The paper then describes the methodology employed and brief overview of the schools and participants students who took part in the study. This is followed by presentation and discussion of the main findings. The paper finally provides conclusion with key lessons and policy that should be considered for designing future school feeding programs.

\section{School feeding programs - an overview}

\section{Impact and efficiency of school feeding programs}

School feeding has two main goals: increased access and participation to education, and increasing learning ability, by improving their nutrition. ${ }^{18}$ Lately, school feeding programs are also used to create structured demand for local produce, hereby improving market integration of local producers and help them transition to modern agriculture. ${ }^{3}$ These programs are politically very popular, and almost all countries, from poor to rich, engage in them. ${ }^{19}$ There are many studies and reviews that examine the effectiveness and benefits of school feeding programs. Review by Jomaa LH et al. ${ }^{20}$ reveal relatively consistent positive effects of school feeding on energy intake, micronutrient status, school enrollment, and attendance of the children participating in school feeding programs compared to non-participants. However, the impact of school feeding on growth, cognition, and academic achievement was less conclusive based on the review by Jomaa LH et al. ${ }^{20}$

The potential impact goal of targeting children through Food for Education programs is to increase their educational achievement so as to improve their potential future productivity and earnings. However, improvement in educational achievement due to serving food in SFPs is thought to occur through three pathways. First, SFP programs increase school attendance by lowering the opportunity costs of attending school and providing additional incentives to engage in formal education. This leads to more time spent in school and more time spent towards learning. The second is through the alleviation of short term hunger which improves children's cognitive functioning and attention span. The third path is through the improved nutritional status of children by providing them calories and nutrients in addition to their regular diet. This leads to better health and better resistance to infectious diseases and illnesses that would keep children from attending school. ${ }^{21}$ Thus, better nutrition indirectly improves educational achievement by increasing school attendance by children. Specially for families facing poverty, food choices are usually limited, resulting in nutritionally inadequate diets that are often deficient in vital micronutrients. ${ }^{22}$ Deficiencies of micronutrients such as iron or vitamin B-12 can result in increased vulnerability to infections, stunted growth and diminished cognitive performance in school-age children. $^{23}$

More recently SFPs have been thought of as a possible tool for agricultural development. ${ }^{3}$ The manner in which these goals link together can be seen in the proposed Home Grown School Feeding (HGSF) programs, which are designed to supply food for SFPs from purchases and procurement of locally produced food while enhancing the domestic production and demand for food. ${ }^{4}$ Traditionally, the procurement of food for SFPs usually came from foreign food aid. When food aid is distributed, there are distortions to the local markets, which often results in lower prices and provide disincentives to local producers. ${ }^{24}$ This has led to the development of programs such as the WFP's Purchase for Progress (P4P) initiative to reverse this trend and helped lead others to look to HGSF as a tool for agricultural development.

The theory for linking SFP to agricultural development begins with a demand shift as the initial kick to the local economy in a HGSF system, as the food previously supplied to the schools came from donors now must be filled by the local producers. The demand is more predictable for producers, which in turn decreases their risk, allowing for more development of local markets. ${ }^{19}$ Increased demand for locally produced food was seen in the case of Indonesia's SFP during the 1990's. In a survey conducted after the economic crisis in Indonesia in 1997-98, 72\% of surveyed farmers reported having more opportunities to sell their produce as a result of the purchases by the SFPs. ${ }^{3}$

A study commissioned by the Millennium Project Task Force on Hunger attempted to shed some light on the potential of locally sourced SFPs in Africa. ${ }^{4}$ In their analysis, the authors conclude that if SFPs with locally produced foods are successful in inducing farmers to adopt modern technology in maize production, they have the potential to substantially benefit producers and consumers throughout sub-Saharan Africa. The study assumes that 50 million primary school-age children in Africa would receive school feeding. They estimate that the supply for maize shifts by 30 percent and the demand curve by 26.6 percent. The total incremental benefits of supplying the programmes with locally produced food were potentially worth about USD 1.6 billion a year in 2003 prices. Of this total, 57 percent would go to consumers and 43 percent to producers.

\section{School feeding program in Ethiopia}

Over the past 20years in collaboration with WFP and other donors, the Ministry of Education, has been implementing school feeding interventions. Currently, through the WFP School Feeding intervention, SFP is being conducted in six regions (Afar, Amhara, Oromia, SNNP, Somali and Tigray). The regional school coverage is: 355 schools in Afar, 146 schools in Amhara, 217 schools in Oromia, 94 schools in SNNP, 229 schools in Somali and 146 schools in Tigray. A total of 1,187 schools and 670,000 students were beneficiaries. Since 2016, Ethiopia government is planning to implement national school feeding programme in all schools as part of the newly developed National School Health Nutrition Strategy. ${ }^{25}$ The government has developed the programme to ensure transition from donor funded programme to national ownership and expand the current coverage to more schools.

\section{Materials and methods}

\section{Overview of study design}

To understand the present status of SFP in Ethiopia and the role of QPM in the program, we first held a consultative workshop with all stakeholders including government and NGOs, seed and grain producers and traders, as well as key policy experts of WFP. This was followed by sensory evaluation trial at two primary schools where 
participating students evaluated food made from both QPM and conventional maize varieties for their sensory characteristics using a scorecard hedonic rating scale. Finally, focus group discussions (FGD) were conducted with the students to complement finding of the sensory evaluation with feedbacks on food samples they tasted.

\section{Stakeholders meeting}

A national stakeholder consultation workshop was organized by the Nutritious Maize for Ethiopia (NuME) project to promote the use of quality protein maize (QPM) in school and refugee feeding programs. The workshop took place in Hawassa on 10 June 2014. It brought together representatives from various organizations engaged in school and refugee feeding programs with the objective to identify existing structural and technical challenges and opportunities to substitute the use of conventional maize with QPM in their respective feeding programs and work out a draft action plan for future efforts.

\section{Sensory evaluation}

\section{Survey instruments and data collection}

Three methods are involved in conducting sensory evaluation, which include; laboratory tests, central location tests (CLT) or home use tests (HUT). ${ }^{26}$ For this study, central location tests (CLT) were used. CLT involves assembling potential purchasers of a product in one central place, may be a school, church or in a hall. The products are prepared out of sight and served on uniform plates uniquely labelled. The potential purchasers are then asked to taste the products and indicate the level of acceptance with a five point hedonic rating scale. In addition, conditions are favorable for a high return of responses from a large sample size. In this method however, the product is usually tested under conditions that are artificial in comparison to normal use at home or in parties or in restaurants. ${ }^{26}$

Participants for the sensory evaluation were drawn from two primary schools, one located in Bure district, Amhara Region, and one in East Badewacho district, in Southern Nations and Nationalities and Peoples Region. The two districts were selected based on their maize production potential as well as the presence of nutrition education in Bure and school feeding program in East Badewacho. In total, 95 adolescent female students participated in the study, 53 from school in Bure and 42 from school in East Badewacho. A popular maize recipe called Kinchie, a porridge like product made from coarsely milled maize grain (grist), was prepared under supervision of a researcher using four different maize varieties: A white conventional maize (BH 660) a white QPM (AMH760Q); a yellow conventional maize (Shaye) and a yellow QPM (BHPQY 545). Equal amount of water, salt and cooking oil were added, and all the food samples were served while hot and presented in a randomized order for the students to taste and evaluate. The products were served on uniquely coded four cups and put on a plate for individual participant to taste and evaluate after receiving instructions on how to undertake the experiment (Figure 1).

Respondents consent was obtained verbally after explanation about the purpose of the research. The respondents were asked to taste the Kinchie, one at a time, and give their response on their perceived level of liking. In this study, a 5-level hedonic scale rating was used, where $1=$ dislike very much, $2=$ dislike, $3=$ either like nor dislike, $4=$ like, and $5=$ like very much. The participants were asked to give their response with respect to taste attributes aroma, appearance, texture, taste and overall acceptability. The order in which the respondents did the evaluation was randomized to avoid positional $\operatorname{error}^{26,27}$ and bottled water was provided to clean their palate in between evaluations (Figure
2). Data on respondents' characteristics and sensory evaluation score of the food samples were recorded on a scorecard provided with the samples. Sensory evaluation of Kinchie porridge made from QPM and conventional maize varieties was conducted in the beginning of July 2015. Maize grain for the experiment was purchased and milled, by a close follow-up of the researchers, and the food was prepared in a standard controlled manner by a food scientist from SG 2000. The evaluation was conducted at $10 \mathrm{AM}$ in the Bure school and at nearly the same time for school in East Badwacho. The questionnaire had two parts, where the first part comprised questions on participant's demographic characteristics such as age, sex, level of education etc., while the second part deals with sensory rating of the food samples using a scorecard. Data was collected by trained enumerators.

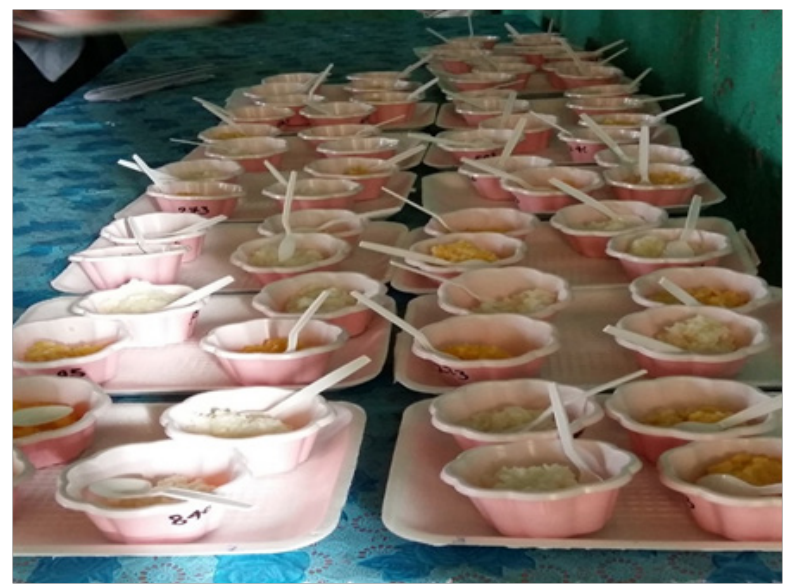

Figure I Presentation of the Kinchie (porridge) made from four different maize varieties, presented in random order, using a neutral code, for sensory evaluation.

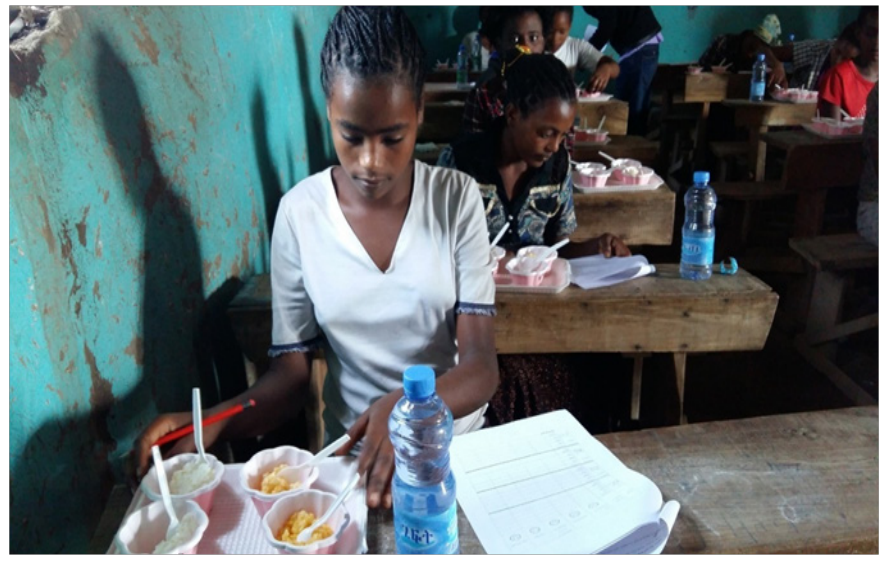

Figure 2 Sensory evaluation of the food samples by adolescent girls in progress.

\section{Data analysis}

To analyze the data, ordinal regression model with random effects was used. The dependent variable $\mathrm{Yi}$ is the overall evaluation rating of both QPM and conventional maize by consumer $i$, using a score from $1-5$, where 1 is very poor and 5 is very good. Ordinal regression estimates the log odds ratio. If consumer scores two products, the log odds ratio estimated is the logarithm of the odds ratio. The odds ratio is the ratio of the odds of one variety receiving a higher score over the odds that the other maize variety receives a higher score. The odds ratio can be calculated as the antilog of the estimated coefficient, the log odds ratio, and indicates how one product was evaluated 
compared to another one. ${ }^{28}$ The method has been used previously with consumers in East Africa both urban ${ }^{29}$ and rural. ${ }^{30}$

\section{Results and discussion}

\section{Stakeholders' meeting}

To understand the current state of school feeding programs in Ethiopia and the role of QPM, a national stakeholder consultation workshop was organized on June 10, 2014 in Hawassa town in Southern Nations, Nationalities \& People's Region (SNNPR). The workshop featured a number of presentations on multiple topics: a brief introduction and overview of the Nutritious Maize for Ethiopia (NuME) project and QPM; the state of child malnutrition in Ethiopia; the nutritional and health benefits of QPM over conventional maize; QPM dissemination success stories from some African countries; the state of QPM dissemination activities in Ethiopia; and some traditional maize recipes. Presenters included CIMMYT scientists and researchers from the Harvard School of Public Health (HSPH), Sasakawa Global-2000 (SG-2000), the Ethiopian Public Health Institute (EPHI) and Hawassa University. In addition, there were presentations on school and refugee feeding experiences by representatives from the World Food Programme (WFP) and the Ministry of Education. The participants from different organizations dealing with maize value chains ranged from heads of farmers' unions to experts from the Ethiopian commodity exchange and federal and regional experts from the ministries of education and health, as well as those working in the UN and other aid organizations. During the workshop, it was noted that maize is the major input in school feeding programs and protein deficiency caused by amino acid imbalance in conventional maize can be addressed by mixing it with legumes (mainly beans) or by substituting QPM for conventional maize.

Based on the outputs of the workshop, NuME project staff members developed short- and medium-term action plans to promote the use of QPM in school and refugee feeding programs. The short-term plan includes selecting one pilot school in SNNPR and implementing a school feeding program using QPM for a semester and then comparing performances with a similar school that uses conventional maize. The results could then be used as a justification to scale up the use of QPM in school feeding throughout the country. In the medium-term, NuME will work with WFP's P4P to replace future conventional maize purchases with QPM through contracts with unions and cooperatives. This will ensure the availability of seeds and lead to adoption by most farmers.

\section{Sensory evaluation}

In line with the recommendations of the workshop, sensory evaluation of QPM preparations were conducted in two schools, using Kinchie prepared from two conventional and two QPM varieties. Participants of the sensory evaluation were 95 adolescent female students drawn from the two study schools: 53 from school in Bure and 42 from school in East Badewacho. The participants were young adolescent girls with an average age of 14.3 years and an average 6.7 years of formal education spent in schooling (Table 1). Adolescent girls were targeted for this study given their role in food preparation and dietary choice decisions in most developing countries. The results sensory evaluation showed that none of the sample food products tasted received the lowest score (as dislike very much). The taste of QPM Kinchie was liked very much by $58 \%$ of the participants, whereas only $1.7 \%$ rated conventional maize Kinchie as having a very good taste. Nobody scored QPM as poor for taste. On the other hand, $0.8 \%$ of the respondents evaluated Kinchie from conventional maize to have a poor taste. Looking at the overall evaluation of the two types of maize varieties, around $61 \%$ of the respondents scored QPM Kinchie as very good, whereas only $5 \%$ of the respondents perceived conventional maize to have very good overall sensory characteristics. Instead, most respondents (58\%) reported CM to have fair overall sensory characteristics. $66 \%$ of the respondents rated QPM Kinchie to have good texture, whereas 21 percent perceived QPM to have very good texture.

Table I Demographic and educational status of the participants

\begin{tabular}{llll}
\hline Kebele & & Age & Education in years completed \\
\hline \multirow{4}{*}{ Arbisi, Bure } & Mean & 14.5 & 6.9 \\
& $\mathrm{~N}$ & 53 & 53 \\
& $\mathrm{SD}$ & 2.1 & 0.9 \\
MehalKorga, & Mean & 14.1 & 6.6 \\
East Badewacho & $\mathrm{N}$ & 42 & 42 \\
& $\mathrm{SD}$ & 1.5 & 0.8 \\
& $\mathrm{Mean}$ & 14.3 & 6.8 \\
Total & $\mathrm{N}$ & 95 & 95 \\
& $\mathrm{SD}$ & 1.9 & 0.9
\end{tabular}

Key: $\mathrm{SD}=$ Standard Deviation

Table 2 Mean scores of Kinchie made from CM and QPM for various sensory characteristics ( $n=95)$

\begin{tabular}{lllllll}
\hline Maize variety & & Appearance & Aroma & Texture & Taste & Overall \\
\hline \multirow{2}{*}{ Conventional White (BH660) } & Mean & 3.75 & 3.54 & 3.58 & 3.47 & 3.85 \\
& SD & 1.35 & 1.31 & 1.3 & 1.28 & 0.95 \\
Conventional Yellow (Shaye) & Mean & 3.77 & 3.8 & 3.6 & 3.66 & 3.86 \\
& SD & 1.36 & 1.22 & 1.39 & 1.32 & 0.99 \\
QPM-Yellow (BHPQY545) & Mean & 4.08 & 3.6 & 3.63 & 4.24 & 4.24 \\
& SD & 1.19 & 1.31 & 1.35 & 1.01 & 0.9 \\
QPM-White (AMHP760Q) & Mean & 3.65 & 3.73 & 3.88 & 3.97 & 4.12 \\
& SD & 1.43 & 1.25 & 1.15 & 1.02 & 0.77 \\
\hline
\end{tabular}

Key: SD=Standard Deviation 
Table 3 Ordinal logistic mixed model results for sensory evaluation test (All maize varieties in the table are compared with white CM)

\begin{tabular}{|c|c|c|c|c|c|}
\hline Variable & Variety & Estimate & SE & P-value & Cox \& Snell \\
\hline \multirow[t]{4}{*}{ Appearance } & Yellow QPM & 3.23 & 0.32 & $.0001 * * *$ & 0.43 \\
\hline & Yellow CM & 0.12 & 0.21 & 0.86 & 0.36 \\
\hline & White QPM & 1.85 & 0.28 & $.000 I^{* * *}$ & 0.45 \\
\hline & Presented first & -0.25 & 0.32 & $0.4 I$ & 0.35 \\
\hline \multirow[t]{4}{*}{ Aroma } & Yellow QPM & 3.11 & 0.34 & $.0001 * * *$ & 0.42 \\
\hline & Yellow CM & 0.24 & 0.29 & 0.43 & 0.37 \\
\hline & White QPM & 1.82 & 0.37 & $.000 I^{* * *}$ & 0.46 \\
\hline & Presented first & 0.64 & 0.34 & $0.02 * *$ & $0.4 I$ \\
\hline \multirow[t]{4}{*}{ Texture } & Yellow QPM & 3.23 & 0.36 & $.000 I^{* * *}$ & 0.43 \\
\hline & Yellow CM & 0.33 & 0.27 & 0.27 & 0.35 \\
\hline & White QPM & 1.88 & 0.35 & $.000 I^{* * *}$ & 0.46 \\
\hline & Presented first & -0.18 & 0.33 & 0.52 & 0.38 \\
\hline \multirow[t]{4}{*}{ Taste } & Yellow QPM & 3.52 & 0.31 & $.0001 * * *$ & 0.42 \\
\hline & Yellow CM & 0.39 & 0.28 & 0.17 & 0.31 \\
\hline & White QPM & 1.88 & 0.33 & $.000 I^{* * *}$ & 0.48 \\
\hline & Presented first & -0.58 & 0.25 & 0.08 & 0.4 \\
\hline \multirow[t]{4}{*}{ Overall } & Yellow QPM & 3.26 & 0.33 & $.000 I^{* * *}$ & 0.44 \\
\hline & Yellow CM & 0.48 & 0.27 & $0.10 *$ & 0.37 \\
\hline & White QPM & 1.98 & 0.34 & $.0001 * * *$ & 0.43 \\
\hline & Presented first & -0.45 & 0.28 & 0.11 & 0.32 \\
\hline
\end{tabular}

Key: SE=Standard Error, Significance: *** $\mathrm{p}<0.001$; ** $\mathrm{p}<0.01$; ${ }^{*} \mathrm{p}<0.0$

Participants were asked to score Kinchie from the four maize varieties, on a 5 point hedonic rating scale. The result of the students' evaluation of the food products revealed that Kinchie made from QPM varieties is much liked for appearance, texture, taste and overall score than one made from conventional maize varieties. In other words, the mean scores of QPM were always higher than those of conventional maize, and therefore more appreciated than conventional maize for all the attributes. Among QPM varieties, the students liked the Kinchie made from yellow QPM (BHQPY 545) more than Kinchie made from a white colored QPM (AMH 760Q) in all sensory attributes except appearance (Table 2). To see if the perceived differences were significantly different, evaluation scores were analyzed using ordinal regression, with "presented first" as a design factor. The result of ordinal regression showed that compared to Kinchie made from white CM, Kinchie made from both white and yellow QPM were significantly rated higher than the control, white $\mathrm{CM}$, in all sensory attributes (Table 3 ). Regression result also showed that order of food presentation did matter only for aroma: the effect was significant and positive only for $\operatorname{aroma}(\mathrm{P}<.05)$, showing that food samples that were served first received higher scores rating for aroma than the samples tasted later. However, order was not significant for the rest of the attributes and overall acceptability.

\section{Conclusion and way forward}

In this study, results of stakeholder consultation meeting showed that there is strong interest by the stakeholders and institutions to use QPM in school feeding programs. Some of the bottlenecks to translate that into action were identified, in particular the lack of seed. Moreover, sensory evaluation of Kinchie prepared from both
QPM and conventional maize by adolescent girls in two study schools showed that Kinchie made from QPM was superior in taste and overall acceptability than Kinchie made from CM. During stockholder consultation meeting, it was noted that most participants agreed on the potentials of QPM to substitute conventional maize in school feeding programs in Ethiopia, and the need for coordination and partnership to realize the intended goal. Furthermore, results of the sensory evaluation with young adolescent girls also showed that both yellow QPM (BHPQY 545) and white QPM (AMHP 760Q) were much appreciated for aroma, taste and overall appreciations. Nevertheless, students liked and appreciated yellow QPM (BHPQY 545) better than the white QPM (AMH 760Q) for appearance, aroma and taste, implying the need for targeted dissemination of the former.

In conclusion, consumer acceptance is unlikely to impede uptake and impact of QPM use in the place of CM varieties in SFPs. In synthesis, this study has demonstrated that QPM gained high consumer acceptability and can have a profound potential in substituting conventional maize use in school feeding programs and thereby address the apparent protein deficiencies in conventional maize varieties. The authors of this study recommend substitution of CM by QPM not only for its nutritional superiority but also for its superior sensory acceptance. Through provision of QPM seeds to local farmers, steady supply of QPM could be ensured through contract farming with programs such as the WFP's Purchase for Progress (P4P) from major maize producing area for school feeding programs. This paper contributes to the literature on using school feeding to promote not only improved nutrition among school children, but also school performance and, through a link with agricultural markets, promote the agricultural transformation of semi-subsistence to commercial 
agriculture by providing a steady demand for agricultural produce. While this study identified stakeholders' interests and sensory appreciation of QPM food product, and the potential role it can play in agricultural development, further study is needed to unveil practical limitations in implementing such model.

\section{Acknowledgements}

The authors thank the study enumerators and are grateful to the women and children who participated in this study. This study was supported by the Nutritious Maize for Ethiopia (NuME) Project (http://nume.cimmyt.org/), led by the International Maize and Wheat Improvement Center (CIMMYT) (http://www.cimmyt.org/) \& funded by Global Affairs Canada (http://www.international.gc.ca/).

\section{Authors' contributions}

DB and HDG conceived the original idea. DB and SYexecuted fieldwork, DB, SY and HDG critically commented on protocol and manuscript. All authors contributed to the refinement of the study protocol and approved the final manuscript.

\section{Conflict of interest}

The authors declare that there is no conflict of interest.

\section{References}

1. Smith P. Delivering food security without increasing pressure on land Global Food Security. 2013;2(1):18-23.

2. EDHS. Ethiopia Mini Demographic and Health Survey; 2014.

3. Sumberg J, R Sabates-Wheeler. Linking agricultural development to school feeding in sub-Saharan Africa: Theoretical perspectives. Food Policy. 2011;36(3):341-349.

4. Ahmed A, M Sharma. Food-for-education programs with locally produced food: effects on farmers and consumers in sub-Saharan Africa Washington: International Food Policy Research Institute. 2004.

5. McEwan PJ. The impact of Chile's school feeding program on education outcomes. Economics of Education Review. 2013;32:122-139.

6. Pollitt E, Gersovitz M, Gargiulo M. Educational benefits of the United States school feeding program: a critical review of the literature. $\mathrm{Am} J$ Public Health. 1978;68(5):477-481

7. Central Statistical Authority. Agricultural Rural Survey Report on Area and Production for Major Crops. 2015. 1 p.

8. Olson RA, Frey K. Nutritional quality of cereal grains: genetic and agronomic improvement: American Society of Agronomy 1987.

9. Bressani R, Elias L, Gomez-Brenes R. Protein quality of opaque-2 corn evaluation in rats. The Journal of nutrition. 1969;97:173-180.

10. Vasal SK. The quality protein maize story. Food and Nutrition Bulletin. 2000;21:445-450.

11. Viteri F, Bressani R. The quality of new sources of protein and their suitability for weanlings and young children. Bull World Health Organ. 1972;46(6):827-843.

12. Gunaratna NS. Evaluating the nutritional impact of maize varieties genetically improved for protein quality. Purdue University. 2007.
13. Johns T, Eyzaguirre PB. Biofortification, biodiversity and diet: A search for complementary applications against poverty and malnutrition. Food Policy. 2007;32(1):1-24.

14. van Jaarsveld PJ, Faber M, Tanumihardjo SA, et al. $\beta$-Carotene-rich orange-fleshed sweet potato improves the vitamin A status of primary school children assessed with the modified-relative-dose-response test. Am J Clin Nutr. 2005;81(5):1080-1087.

15. Haas JD, Beard JL, Murray-Kolb LE, et al. Iron-biofortified rice improves the iron stores of nonanemic Filipino women. The Journal of nutrition. 2005; 135(12):2823-2830.

16. van Stuijvenberg ME, Kvalsvig JD, Faber M, et al. Effect of iron-, iodine-, and $\beta$-carotene-fortified biscuits on the micronutrient status of primary school children: a randomized controlled trial. Am J Clin Nutr. 1999;69(3):497-503.

17. Ahenkora K, Twumasi-Afriyie S, Sallah PYK, et al. Protein nutritional quality and consumer acceptability of tropical Ghanaian quality protein maize. Food and Nutrition Bulletin. 1999;20:354-360.

18. Kristjansson EA, Gelli A, Welch V, et al. Costs, and cost-outcome of school feeding programmes and feeding programmes for young children. Evidence and recommendations. International Journal of Educational Development. 2016;48:79-83.

19. Bundy D, Burbano C, Grosh M, et al. Rethinking school feeding: social safety nets, child development, and the education sector. World Bank Publications. 2009

20. Jomaa LH, McDonnell E, Probart C. School feeding programs in developing countries: impacts on children's health and educational outcomes. Nutr Rev. 2011;69(2):83-98.

21. Buttenheim A, Alderman H, Friedman J. Impact evaluation of school feeding programmes in Lao People's Democratic Republic. Journal of Development Effectiveness. 2011;3:520-542.

22. Ash DM, Tatala SR, Frongillo EA, et al. Randomized efficacy trial of a micronutrient-fortified beverage in primary school children in Tanzania. Am J Clin Nutr. 2003;77(4):891-898.

23. Arsenault JE, Mora-Plazas M, Forero Y, et al. Provision of a school snack is associated with vitamin B-12 status, linear growth, and morbidity in children from Bogota, Colombia. J Nutr. 2009;139(9):1744-1750.

24. Barrett C. Food aid's intended and unintended consequences. 2006

25. Ethiopian Herald National school feeding programme to be applied in all schools. 2016.

26. Meilgaard M, Civille G, Carr B. Introduction to sensory techniques. Boca Raton, FL: CRC Press; 2007:1-5.

27. Watts BM, Ylimaki G, Jeffery L, et al. Basic sensory methods for food evaluation. Ottawa, ON, CA: IDRC; 1989.

28. Meullenet JF, Xiong R, Findlay CJ. Multivariate and probabilistic analyses of sensory science problems. Wiley Online Library. 2007.

29. De Groote H, Gunaratna NS, Okuro JO, et al. Consumer acceptance of quality protein maize (QPM) in East Africa. J Sci Food Agric. 2014;94(15):3201-3212.

30. Gunaratna NS, Bosha T, Belayneh D, et al. Women's and children's acceptance of biofortified quality protein maize for complementary feeding in rural Ethiopia. J Sci Food Agric. 2016;96(10):3439-3445. 